\title{
ИССЛЕДОВАНИЕ УРОВНЯ ГОТОВНОСТИ ПЕДАГОГОВ ДЛЯ РАБОТЫ В УСЛОВИЯХ ИНКЛЮЗИВНОГО ОБРАЗОВАНИЯ В КИТАЕ
}

\section{RESEARCH OF THE LEVEL OF PREPAREDNESS OF TEACHERS TO WORK IN CONDITIONS OF INCLUSIVE EDUCATION IN CHINA}

Zheng Lingling

Summary: The article examines the readiness of teachers to work in inclusive education in China using the questionnaire "Determining the readiness of teachers to work with children with disabilities» (material from the electronic journal «Primary School Management» January 2018). The analysis of the results on the levels of knowledge, psychological and professional readiness of Chinese teachers is made. Some problematic issues of teachers' readiness to work in inclusive education are considered. Such problems are insufficient knowledge about inclusive education and the developmental characteristics of children with disabilities, and psychological readiness to work with any students, lack of confidence in their professional readiness. The directions of increasing the readiness of teachers for the implementation of inclusive education in China are indicated.

Keywords: inclusive Education, Children with Disabilities, Teacher Preparation for Inclusive Education, Learning in the Regular Classroom (LRC).

\author{
Чжэн Линлин \\ Аспирантура, МГУ имени М.В. Ломоносова \\ mangolingling@yandex.ru
}

Аннотация: В статье рассмотрены готовности педагогов к работе в условиях инклюзивного образования в Китае с помощью анкеты «Определение готовности педагогов к работе с детьми с ОВЗ» (материал электронный журнала «Управление начальной школой» январь 2018 г.). (делан анализ результатов 06 уровнях знаниевой, психологической и профессиональной готовности китайских педагогов. Рассмотрены некоторые проблемные вопросы готовности педагогов к работе в условиях инклюзивного образования. Такими проблемами являются недостаточные знание об инклюзивном образовании и особенностях развития детей с ограниченными возможностями здоровья, и психологическая готовность к работе с любыми учащимися, отсутствие уверенности своей профессиональной готовности. Указаны направления повышения готовности педагогов для реализации инклюзивного образования в Китае.

Ключевые слова: инклюзивное образование, дети с ограниченными возможностями здоровья (овз), готовность педагогов к инклюзивному образованию.

ванию для детей школьного возраста с ограниченными возможностями, развитию инклюзивного образования и сочетанию методов медицины и образования» [3].

В настоящее время основным способом инклюзивного образования в Китае являются обучению в обычном классе (известно как «вслед за классом», англ. «Learning in Regular (lass») и обучению в специальном классе в обычной школе. По состоянию на 2020 г. число особых детей на обучении в обычных классах в обычных школах, приближается к 436 тыс., что составляет 49,5\% от общего числа особых детей на обучении (См. Таблицу 1.). За последние пять лет общее число особых учащихся на обучении увеличилось в 1,8 раза больше, с 490 тыс. до 880 тыс. Число учащихся с ОВ3 в обычных классах и в специальных классах в обычных школах также возрастает из года в год, но процентное соотношение между числом учащихся с ОВ3 в обычных классах обычных школ и общим числом учащихся с ОВ3 изменилось с 54,4\% до $49,5 \%$, а процентное соотношение между числом учащихся с ОВ3 в специальных классах обычных школ и общим числом учащихся с ОВ3- с 0,69\% до 0,48\%. Следовательно, развитие инклюзивного образования в Китае 
Таблица 1

Число особых учащихся, число особых учащихся в обычных школах и в специальных школах в Китае

\begin{tabular}{|c|c|c|c|c|c|}
\hline & 2016 г. & 2017 г. & 2018 г. & 2019 г. & 2020 г. \\
\hline $\begin{array}{c}\text { Общее число особых } \\
\text { учащихся }\end{array}$ & 491740 & 578826 & 665942 & 794612 & 880800 \\
\hline Число особых учащихся & 267452 & 300814 & 329068 & 390525 & 435756 \\
в обычных классах & $(54.4 \%)$ & $(52 \%)$ & $(49.4 \%)$ & $(49.1 \%)$ & $(49.5 \%)$ \\
\hline Число особых учащихся & 3370 & 3459 & 3072 & 3845 & 4211 \\
в специальных классах & $(0.69 \%)$ & $(0.6 \%)$ & $(0.46 \%)$ & $(0.48 \%)$ & $(0.48 \%)$ \\
\hline
\end{tabular}

не было таким успешным, как ожидалось. Для более чем половины особых учащихся основным способом получения образования являются обучение в специальной школе, а не в обычной школе.

В январе 2019 г. клуб Янай для родителей детей с ОВ3 (частная благотворительная организация в городе Гуанчжоу) опубликовал «Отчет о поступлении в школу детей с ОВ3 школьного возраста в городе Гуанчжоу» [4]. Отчет отметил, что среди 112 респондентов (детей с ОВ3), подавших заявления о поступлении в школу в 2017 г., 88\% успешно поступили; после поступления более половины детей с особыми потребностями заявили, что они более приспособлены к учебе и жизни в общеобразовательной школе, и 43\% особых детей школьного возраста заявили, что 43\% детей школьного возраста заявили, что им все еще трудно интегрироваться в обычные школы; трудности с интеграцией в обычные школы включают отсутствие опыта педагогов работы с детьми с ОВ3 (68\%), отсутствие компетентных педагогов специального образования(73\%), нетерпимости, антипатии и непринятия у здоровых детей(30\%).

Особые дети поступают в обычные школы после многочисленных трудностей, но из-за отсутствия подходящей образовательной среды и компетентных педагогов инклюзивного образования это часто приводит к тому, что «обучение вслед за классом» становится «сидением вслед за классом». Одним из самых больших препятствий на пути повышения качества инклюзивного образования является отсутствие квалифицированных педагогов, которые могут обеспечить организацию по работе в области инклюзивного образования [5, с.56].

Это исследование направлено на понимание готовности педагогов к работе с детьми с ОВЗ в условиях инклюзивного образования в Китае с помощью анкеты. Респондентами являются педагоги, работающие в обычных школах, специальных школах и других образовательных учреждениях в Китае. Анкеты заполняются педагогами анонимно онлайн, было собрано 136 действительных анкет. Основное содержание анкеты относится к анкете «Определение готовности педагогов к работе с детьми с ОВ3», опубликованной в январе 2018 г. российским электронным журналом «Управление начальной школой».
Соответствующее содержание с Федеральным Законом «Об образовании в Российской Федерации» было удалено, а основа и интерпретация анкеты были переведены на китайский язык. В начале новой анкеты был добавлен дополнительный вопрос о месте работы педагогов (См. Таблица 2.).

Таблица 2

Места работы педагогов-респондентов (общее число:136)

\begin{tabular}{|c|c|c|c|}
\hline \multirow{4}{*}{ Место } & Число & $\begin{array}{c}\text { Процент } \\
\text { работы }\end{array}$ \\
\cline { 2 - 4 } & Общеобразовательные школы & 85 & $62.5 \%$ \\
\cline { 2 - 4 } & $\begin{array}{c}\text { Образовательные учреждении } \\
\text { инклюзивного образования }\end{array}$ & 4 & $2.9 \%$ \\
\cline { 2 - 4 } & $\begin{array}{c}\text { Другие образовательные } \\
\text { организации }\end{array}$ & 45 & $33.1 \%$ \\
\hline
\end{tabular}

Эта анкета разделенные на три части: первая часть характеризует уровень знаниевой готовности педагогов к работе с особыми детьми, вторая часть - уровень психологической готовности, третья часть - уровень профессиональной готовности. Для каждого вопроса педагоги должны выбрать наиболее подходящий ответ из 3 или 4 вариантов в зависимости от реальной ситуации, каждый вариант ответа соответствует одну баллу (0-2 балла). После заполнения анкеты подсчитывается общий балл, чтобы знать какой уровень готовности педагогов к работе с детьми с ОВ3. Чем больше количества баллов, тем выше уровня готовности педагогов: 43-52 баллов (именно высокий уровень готовности); 22-42 баллов (средний уровень);0-21 баллов (низкий уровень). Согласно результатам анкет, среди 136 респондентов, ни один из их не достигнул высокого уровня готовности, 82 педагогов- на среднем уровне (60,3\%), а 54 - на низком уровне (39,7\%). Средний балл анкет для всех респондентов составляет 23,3 балла, который находится на среднем уровне (22-42 баллов).

Высказывании первой части (общее количество баллов-20, средний балл респондентов-7.9) в основном характеризует уровень овладения знаниями о детях с ОВ3 и организациях развития инклюзивного образования. По представлениям об инклюзивном образовании, 12\% 
респондентов хорошо понимают и могут объяснять особенности такого образования, 54\%- имеют ограниченные знания, а 34\%- не имеют представлений об этом образовании. Это показывает, что знание и представление инклюзивного образования еще не получила полной популярности среди педагогов в Китае, исключая педагогов в области специального образования или инклюзивного образования.

Среди 136 педагогов, принявших участие в анкетировании, 92 из них (68\%) думают, что у них специальные знания для организации работы с детьми с ОВЗ отсутствуют, а 41 респондентов (30.1\%) имеются минимальные такие знания. В то же время 59\% педагогов считают, что им необходимо получить дополнительное образование по коррекционной педагогике и коррекционной психологии, 37\% хотят повысить квалификацию по коррекционной педагогике и коррекционной психологии, и только 4\% считают, что их квалификация в такие области достаточна. Это показывает, что почти все респонденты не обладают достаточными специальными знаниями, чтобы заниматься работой с детьми с ОВ3, и для них существуют потребности в повышении квалификации по коррекционной педагогике и коррекционной психологии.

Ответы на высказывания второй части (общее количество баллов-20, средний балл респондентов-8.9), в основном, характеризуют психологической готовности педагогов для организации работы с детьми с ОВ3.

Работа с детьми с особыми потребностями - непростая задача, только у 7\% педагогов полностью сформирована психологическая готовность. Для остальных педагогов такая готовность либо еще постепенно, а не полностью формируется (для 71\% респондентов), либо не сформирована вообще (для $22 \%$ респондентов). По мнению педагогов, если дети с ОВЗ включены в инклюзивную образовательную систему, у них главное опасение заключается в том, что дети с особыми потребностями не усвоят то, что могли бы усвоить в специальной школе (у 52\% респондентов). Для 33\% педагогов, главное препятствие - здоровые дети будут ущемлены в правах, и педагогам будет уделяться меньше времени на урок, а также 15\% педагогов считают свои страх и брезгливость как главное препятствие.

Последняя часть анкеты связана с уровнем профессиональной готовности педагогов к работе с детьми с OB3. В этой части количество баллов-12, а средний балл респондентов составляет 6,4 балла.

Подавляющее большинство педагогов не обладают профессиональными готовностями для работы с особыми детьми. Если бы в классе или группе был учащийся с ОВ3, 70\% педагогов попросили бы обратиться за помощью к специалистам и коллегам, имеющим опыт такой работы, а 26\% педагогов попросили бы перевести особый учащийся в другой класс или группу, потому что у них нет опыта к работе с учащимся с OB3, и только 4\% говорят, что для них проблем не будет, они могут справиться. В то же время, с появлением особых детей в классе или группе, респонденты считают, что нужно изменить в работе: применение специальных технологий и методов обучения (55\%), а также использование особых дидактических материалов и специального оборудования (44\%). Это доказывает, что большинство учителей понимают, что профессиональные сопровождении также должны быть изменены при работе с детьми с ОВ3. По сравнению с особыми материалами и специальными оборудованием, применение специальных технологии и методов обучения больше пользуется вниманием респондентов.

График 1 Распределение баллов по трем готовностям

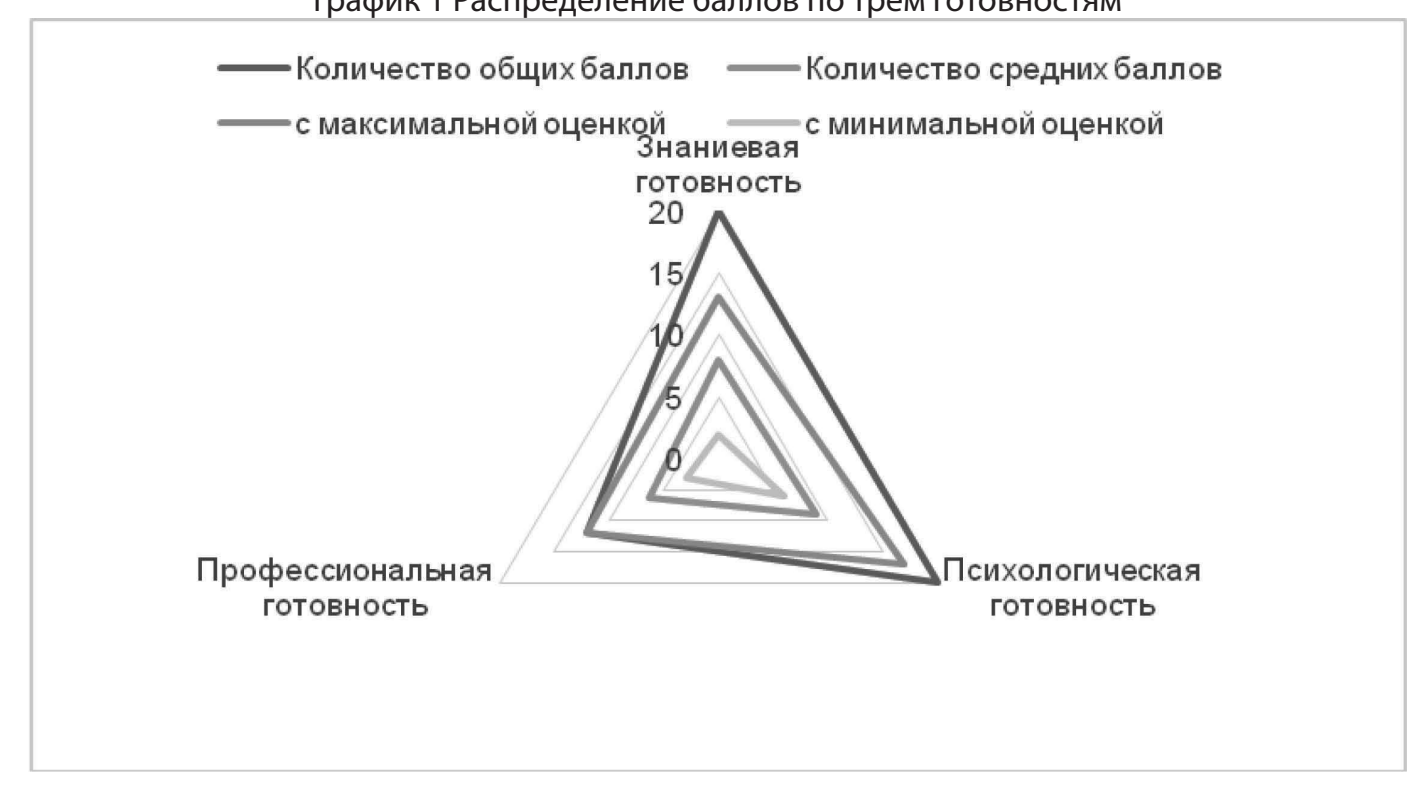


Согласно результатам анкеты, готовность респондентов к работе с детьми с ОВЗ находится на среднем уровне (См. График 1.), значит у респондентов недостаточно знаний об инклюзивном образовании и работе с особыми детьми, и психологическая готовность к совместной работе с детьми с ОВЗ еще сформирована. Пока не готовы к организации инклюзивного образования с разными детьми при использовании научных способов и специальных педагогических технологий, но возникают желание или необходимость повышения квалификации для проведения инклюзивного образования. Хотя респонденты не являются репрезентативными для всех педагогов в Китае, они также в определенной степени отражают недостаточные готовности педагогов при реализации инклюзивного образования в Китае, и знаниевая готовность, и психологическая готовность, и профессиональная готовность. Сравнивая средние баллы респондентов по трем готовностям, можно увидеть, что уровень знаниевой готовности у респондентов относительно самый низкий, даже для респондента с максимальной оценкой.

Большая часть респондентов, осознавала свою нехватку знаний в области инклюзивного образования, и в то же время выражала желание и необходимость повышать свою квалификацию для реализации инклюзивного образования с детьми с ОВ3. Если можно будет организовать дополнительное обучение в области инклюзивного образования, это значительно повысит готовность принятия на работу с особыми детьми. Для педагогов, которые на данный момент не имеют опыт в области специального образования или работы, связанной с инклюзивным образованием, могут соответствующим образом добавить знания об инклюзивном образовании и индивидуальных особенностях развития детей с ОВ3, чтобы распространять основные знания в сфере инклюзивного образования. Текущее обучение для педагогов, которые занимаются работой с особыми детьми, в основном сосредоточена на индивидуальных особенностях развития детей с ОВ3, специальных методах обучения для особых детей и реализации ресурсных классов. Однако обучение о корректировке учебной программы, общении и сотрудничестве, а также знание по соответствующим законам и политике в Китае не достаточны [6, с.4]. В связи с этим, могут быть интегрированы ресурсы разных школ или разных регионов для усиления информационного обмена между педагогами из разных образовательных учреждений (с программами по работе с особыми детьми или без таких программ). Посредством лекций, краткосрочного обучения, наблюдения в классе и других способов, постепенно формируют необходимые знания по законам и документам о развитии и обеспечении инклюзивного образования, профессиональные умения и навыки к организации обучения детей с ОВ3, чтобы уменьшить их опасение перед особыми детьми и работами в условиях инклюзивного образования, повышать их способности сотрудничества с другими участниками инклюзивного образования и готовности при организации работы совместного образования и особых детей и здоровых детей школьного возраста.

\section{ЛИТЕРАТУРА}

1. Некоторые замечания о развитии специального образования. Государственный комитет по образованию и другие восемь министерств и комиссий. [Электронный ресурc] URL: https://www.cnki.com.cn/Article/CJFDTotal-GWYB198913008.htm (Дата обращения 28.09.2021)

2. Положение об образовании инвалидов. Госсовет КНР. [Электронный ресурс] URL: http://www.gov.cn/gongbao/content/2017/content_5178184.htm(Дата обращения 28.09.2021)

3. Модернизация образования в Китае до 2035 г. Центральный комитет Коммунистической партии Китая с Госсоветом. [Электронный ресурс] URL: http://www.moe.gov.cn/jyb_xwfb/gzdt_gzdt/201902/t20190223_370857.html (Дата обращения 28.09.2021)

4. Отчет о поступлении в школу детей с ОВЗ школьного возраста в городе Гуанчжоу. Клуб Янай для родителей детей с ОВЗ. [Электронный ресурс] URL:http://www.Xxsb.com/content/2019-01/13/content_42511.html (Дата обращения 28.09.2021)

5. Лю Чуньлин. Повышение качество инклюзивного образования. // Журнал инвалидов в Китае. 2010, №4. С. 56. doi: CNKI: SUN: CJRZ.0.2010-04-030

6. Фэн Яцин. Исследование основных профессиональных качеств педагогов по обучению в обычных классах. // Журнал специального образования в Китае. 2014, №1. C. 4. doi: 10.3969/j.issn.1007-3728.2014.01.002 